Erratum

\title{
Erratum to "Investigation of Sesamol on Myeloperoxidase and Colon Morphology in Acetic Acid-Induced Inflammatory Bowel Disorder in Albino Rats"
}

\author{
Phani Krishna Kondamudi, Hemalatha Kovelamudi, Geetha Mathew, Pawan G. Nayak, \\ Mallikarjuna C. Rao, and Rekha R. Shenoy
}

Department of Pharmacology, Manipal College of Pharmaceutical Sciences, Manipal University, Manipal, Karnataka 576104, India

Correspondence should be addressed to Rekha R. Shenoy; rekha.shenoy@manipal.edu

Received 24 March 2014; Accepted 8 April 2014; Published 14 April 2014

Copyright (C) 2014 Phani Krishna Kondamudi et al. This is an open access article distributed under the Creative Commons Attribution License, which permits unrestricted use, distribution, and reproduction in any medium, provided the original work is properly cited.

In the original paper, there was an error in Figure 7(a). Figures 7 (a) and 7 (d) were the same. Here, we provide the right form of Figure $7(a)$.

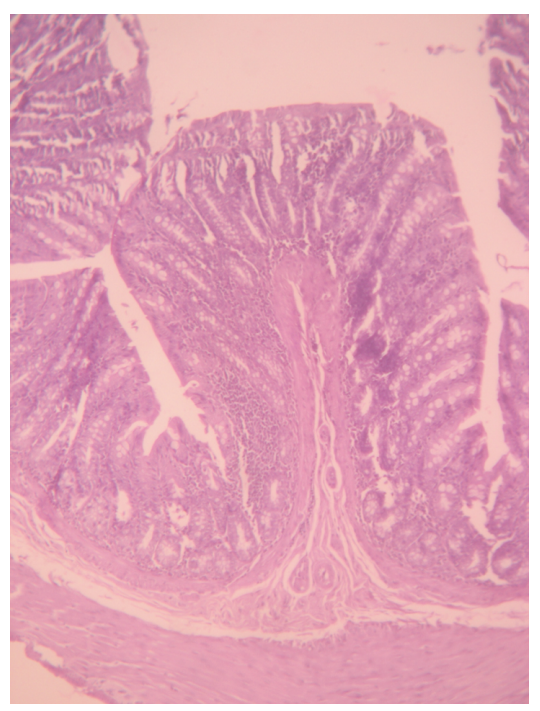

(a)

FiguRe 7 

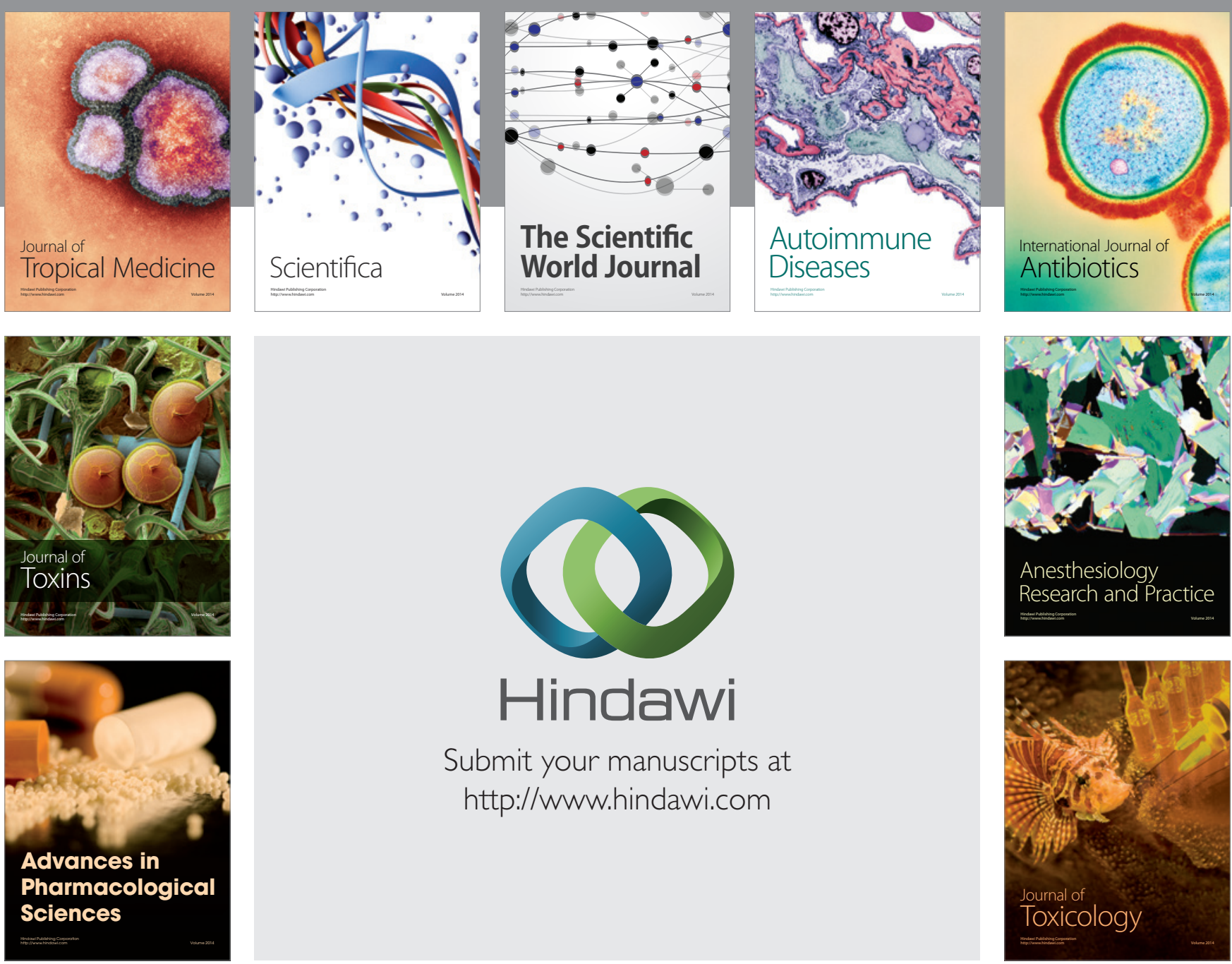

\section{Hindawi}

Submit your manuscripts at

http://www.hindawi.com
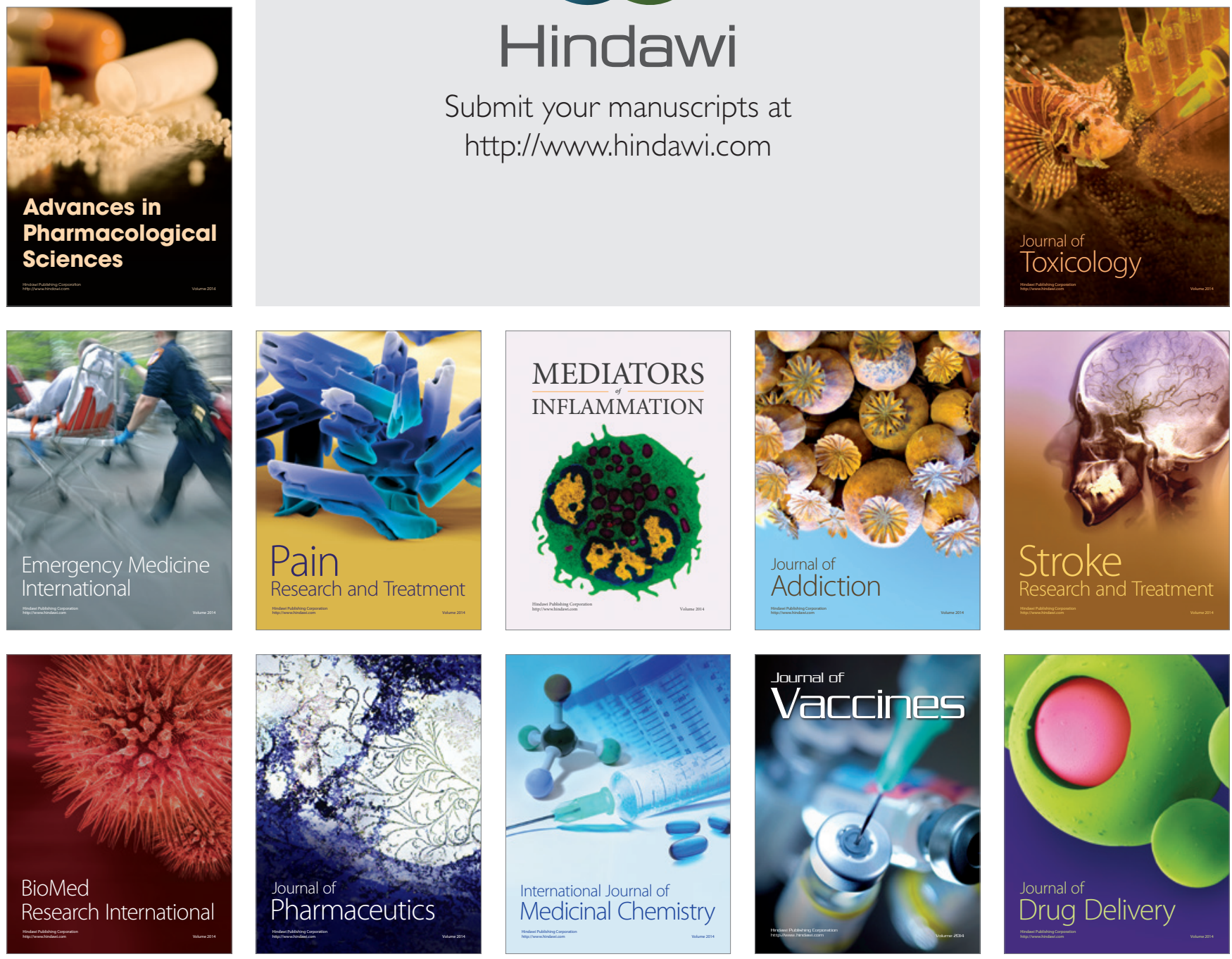